\title{
Crack opening behavior in ceramic matrix composites
}

\author{
Kathleen M. Sevener ${ }^{1}$ (D) | Jared M. Tracy ${ }^{1}$ | Zhe Chen ${ }^{2}$ | James D. Kiser ${ }^{3}$ | \\ Samantha Daly ${ }^{2}$
}

${ }^{1}$ Department of Materials Science and Engineering, University of Michigan, Ann Arbor, Michigan

${ }^{2}$ Department of Mechanical Engineering, University of California, Santa Barbara, California

${ }^{3}$ NASA Glenn Research Center,

Cleveland, Ohio

\section{Correspondence}

Kathleen M. Sevener, Department of Materials Science and Engineering,

University of Michigan, Ann Arbor, MI.

Email: ksevener@umich.edu

Funding information

NASA Glenn Research Center, Grant/

Award Number: F039383-079382

\begin{abstract}
The evolution of matrix cracks in a melt-infiltrated $\mathrm{SiC} / \mathrm{SiC}$ ceramic matrix composite (CMC) under uniaxial tension was examined using scanning electron microscopy (SEM) combined with digital image correlation (DIC) and manual crack opening displacement (COD) measurements. CMC modeling and life prediction strongly depend a thorough understanding of when matrix cracks occur, the extent of cracking for given conditions (time-temperature-environment-stress), and the interactions of matrix cracks with fibers and interfaces. In this work, strain relaxation due to matrix cracking, the relationship between CODs and applied stress, and damage evolution at stresses below the proportional limit were assessed. Direct experimental observation of strain relaxation adjacent to regions of matrix cracking is presented and discussed. Additionally, crack openings were found to increase linearly with increasing applied stress, and no crack was found to pass fully through the gage cross-section. This calls into question the modeling assumption of through-cracks for all loading conditions and fiber architectures, which can obscure oxidation mechanisms that are active in realistic cracking conditions. Finally, the combination of SEM with DIC is demonstrated throughout to be a powerful means for damage identification and quantification in CMCs at stresses well below the proportional limit.
\end{abstract}

\section{K E Y W O R D S}

ceramic matrix composites, cracks/cracking, damage, silicon carbide

\section{1 | INTRODUCTION}

The use of ceramic matrix composites (CMCs) in high temperature aerospace applications is rapidly increasing. Woven silicon carbide ( $\mathrm{SiC})$ fiber-reinforced melt-infiltrated (MI) silicon carbide matrix composites are prominent candidates for these applications because the material system offers significant structural performance retention at elevated temperatures, and the woven architecture can offer improved component fabricability. ${ }^{1-7}$

Matrix cracking is a critical damage mechanism in these composites, where the extent of matrix cracking depends on parameters including fiber type and architecture, interphase composition, constituent volume fractions, and constituent properties. ${ }^{8-13}$ CMCs are thereby designed to accommodate matrix cracking through interface debonding and crack deflection. This matrix crack accommodation enables advantageous properties of CMCs including toughness and non-catastrophic fracture behavior. However, matrix cracking also provides pathways for oxidizing vapor species such as $\mathrm{O}_{2}$ and $\mathrm{H}_{2} \mathrm{O}$ to penetrate the composite, leading to reactions with the constituents and subsequent strength degradation. ${ }^{14-22}$

CMC modeling and life prediction require a thorough understanding of when matrix cracks occur, the extent of cracking for given conditions (time-temperature-environment-stress), and the interactions of matrix cracks with fibers and interfaces. Due to the substantial impact that 
oxidation can have on composite life, there is considerable effort to model oxidation of $\mathrm{SiC} / \mathrm{SiC}$ CMCs. ${ }^{23-28}$ These oxidation models each approach oxidation with a different focus, but all require knowledge of the matrix crack evolution with increasing applied stress. Significant work has been performed to measure and model matrix crack densities and observe crack pathways, but there has been limited research on crack opening displacements. ${ }^{8-11,29-34}$ Crack opening displacement (COD) is a function of the applied stress. While CODs can be calculated, ${ }^{9,15,35,36}$ most models consider unidirectional reinforcement and require constituent parameters, like interfacial shear stress, that are difficult to measure and are often approximated from other measurements. Direct experimental measurements of COD values are largely unavailable with references ${ }^{10,34,37,38}$ being the exceptions. In this study, we investigate matrix crack evolution in an $\mathrm{MI} \mathrm{SiC/SiC} \mathrm{CMC} \mathrm{subjected} \mathrm{to} \mathrm{uniax-}$ ial tensile loading in a scanning electron microscope using both digital image correlation and manual COD measurements. Evolution of damage at stresses below the proportional limit, strain relaxation due to matrix cracking, and the relationship between COD and stress are assessed.

\section{2 | EXPERIMENTAL METHODOLOGY}

\section{1 $\mathrm{SiC} / \mathrm{SiC}$ panel fabrication}

A slurry-cast, melt infiltrated (MI) $\mathrm{SiC} / \mathrm{SiC}$ fabricated by GE Power Systems Composites (GEPSC Newark, DE), was evaluated. This $\mathrm{SiC} / \mathrm{SiC}$ material was developed in the Enabling Propulsion Materials program, which was conducted by a partnership between NASA, General Electric, and Pratt and Whitney as part of the High Speed Research program. ${ }^{1}$ Tensile coupons were extracted from a panel that was fabricated as follows: NASA GRC provided an eightply "preform" or stack of 20 ends per inch, 5 harness satin weave Sylramic ${ }^{\mathrm{TM}} \mathrm{SiC}$ fabric (Dow Corning, Midland, MI, USA). The fiber content was balanced in the two orthogonal directions in this $0 / 90^{\circ}$ fabric. GEPSC assembled the stacked cloth into CVI (chemical vapor infiltration) tooling and deposited a Si-doped BN fiber coating. CVI SiC was then deposited until the resulting preform contained sufficient $\mathrm{SiC}$ matrix material to rigidize the stack of fiber plies, following which the tooling was removed. Additional CVI $\mathrm{SiC}$ was deposited leaving interconnected (inter-tow) porosity. The remaining matrix was formed by infiltrating a slurry that contained $\mathrm{SiC}$ particulates into the interconnected porosity, removing the liquid from the slurry, and then infiltrating those particles with molten silicon to form a highly dense composite with high thermal conductivity. General overviews describing this processing approach are provided in, ${ }^{6,39}$ along with additional information about the advantages and disadvantages of this type of $\mathrm{MI} \mathrm{SiC} / \mathrm{SiC}$ CMC. The resultant panel had a final bulk density of $2.78 \mathrm{~g} / \mathrm{cm}^{3}$ as determined by GEPCS via the Archimedes method.

\section{2 | Specimen machining}

A rectangular specimen blank of the CMC was cut with a diamond saw with sides parallel to the orientation of the 2D fiber reinforcement $0^{\circ}$ and $90^{\circ}$ tows. A machining coolant solution consisting of a 40:1 water:fluid ratio (LongLife 20/20 Plus Super Synthetic Multipurpose Metalworking Fluid) was used during the cutting and contouring of the rectangular shape. The dimensions of the tensile specimen are shown in Figure 1 and were produced via a computer-aided manufacturing system that used a computeraided design file to guide a computerized numerical control machine. The rectangular CMC blank was held with clamps, and a "bow-tie" contour was machined on one side of the specimen with a diamond tool. The piece was then rotated by $180^{\circ}$ and the second "bow-tie" contour was machined. The measured specimen dimensions were within $\pm 0.01 \mathrm{~mm}$ tolerance. The machined specimen was rinsed in ethanol.

\section{3 | Sample surface preparation}

One edge of the machined test specimen was polished to a $1 \mu \mathrm{m}$ finish to facilitate microscale deformation tracking via a combination of digital image correlation (DIC) and scanning electron microscopy (SEM), termed here as SEMDIC. DIC is an experimental technique that calculates fullfield displacements, and resulting strains, through the comparison of a speckle pattern on the surface in an unloaded (reference) image to images of the deformed surface taken during subsequent loading steps. ${ }^{40}$ In SEM-DIC, subsets of nanoparticles are applied to the surface of a test specimen and are tracked during deformation in order to calculate microscale strain fields (for a detailed description of this approach, please see ${ }^{41-43}$ ). In 2015, Tracy et al.

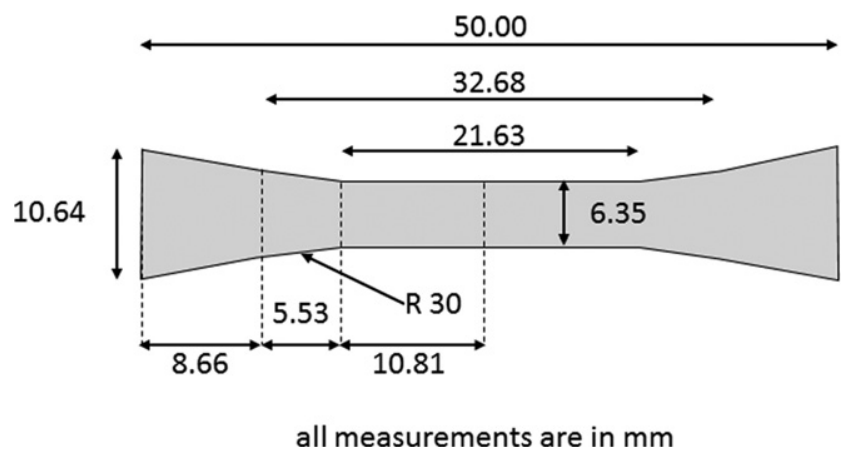

FIGURE 1 CMC specimen geometry with dimensions in $\mathrm{mm}$ and tolerances of $\pm 0.01 \mathrm{~mm}$ 


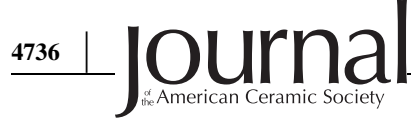

demonstrated the use of SEM-DIC for the quantification of constituent scale damage evolution in CMCs. ${ }^{37}$ To prepare the specimens for in-SEM deformation tracking, the edge was first ground using a $10 \mu \mathrm{m}$ diamond disk, then polished successively with 9,3 , and $1 \mu \mathrm{m}$ paste (Buehler MetaDi II, Lake Bluff, IL, USA) suspended on Texmet cloths (Buehler) using non-aqueous suspension fluid. Between each polishing step, the sample was cleaned with methanol in an ultrasonic bath. After final polishing, the sample was cleaned, using ultrasonic agitation, in steps with three different solvents (acetone, isopropyl alcohol, and methanol) to remove the residual polishing media from pores in the sample. The sample surface was then functionalized with 3-mercaptopropyl methyl dimethoxysilane and patterned with $60 \mathrm{~nm}$ Au nanoparticles for SEM-DIC following the procedure outlined in Ref. [44].

\section{4 $\mid$ Tensile testing and COD measurements}

Testing was conducted at room temperature in an SEM (Tescan MIRA3, Tescan, Kohoutovice, Czech Republic) using an in-situ tensile stage (Kammrath \& Weiss, Dortmund, Germany) with a $5 \mathrm{kN}$ load cell. The experimental setup is shown in Figure 2. During testing, the sample was imaged with an approximately $500 \mu \mathrm{m} \times 200 \mu \mathrm{m}$ area of interest (AOI) at each loading increment. The loading increments were equivalent to far field stresses of approximately $0,35,70,105,140,175$, and $210 \mathrm{MPa}$, respectively. Figure 2 shows the tensile bar mounted in the dovetail grips from the load frame. The inset outlined in red shows an SEM micrograph of the polished sample surface, and the black box within that image highlights the region of the cross-section imaged for SEM-DIC. Figure 3 shows the orientation of the microstructure relative to the loading axis and outlines the AOI comprised of ten fields of view (FOVs), imaged at each loading step during tensile testing.
The inset in Figure 3 shows the microstructure within one FOV, with $\mathrm{Au}$ nanoparticles deposited for deformation tracking by SEM-DIC. For reference, the inset to the left in the figure includes a representative sample of the nanoparticle pattern at increased magnification. Note that the speckle size and distribution allowed for DIC subset (facet) sizes as fine as 75 image pixels (i.e., $3.7 \%$ of the field width of each image).

Uniaxial tensile testing was performed for a total of three loading cycles. In the first cycle, load was applied in increments of approximately $35 \mathrm{MPa}$. The macroscopic stress-displacement curves for the first loading cycle and second reloading cycle are shown in Figure 4. Note that specimen extension was measured by an LVDT attached to the drive train of the load frame. The large elongation values reported in Figure 4 are attributed to specimen extension as well as to system compliance in the load frame (primarily elastic deformation of the steel dovetail grip assembly), and are not exclusively indicative of uniaxial strain in the specimen's gage section. A small amount of relaxation, evidenced by a small load drop in Figure 4, occurred at each hold. The sample was allowed to fully relax before imaging, which took approximately one minute. Between 140-175 MPa, matrix cracking started, as shown at the constituent length scale in Figure 5 and evidenced by the large load drop in Figure 4. At $175 \mathrm{MPa}$, a matrix crack was identified $\sim 75 \mu \mathrm{m}$ to the right of the original AOI (Figure 5). The specimen was then unloaded to $0 \mathrm{MPa}$ and a reference image for SEM-DIC was taken of a new AOI containing this matrix crack. The specimen was then reloaded to $210 \mathrm{MPa}$ with micrographs taken at $35 \mathrm{MPa}$ steps for SEM-DIC. All SEM micrographs were captured using an accelerating voltage of $20 \mathrm{kV}$ at a working distance of $24 \mathrm{~mm}$. Image size was maintained at $2048 \times 2048$ pixels while the magnification and the field of view varied. Following loading to $210 \mathrm{MPa}$, the sample

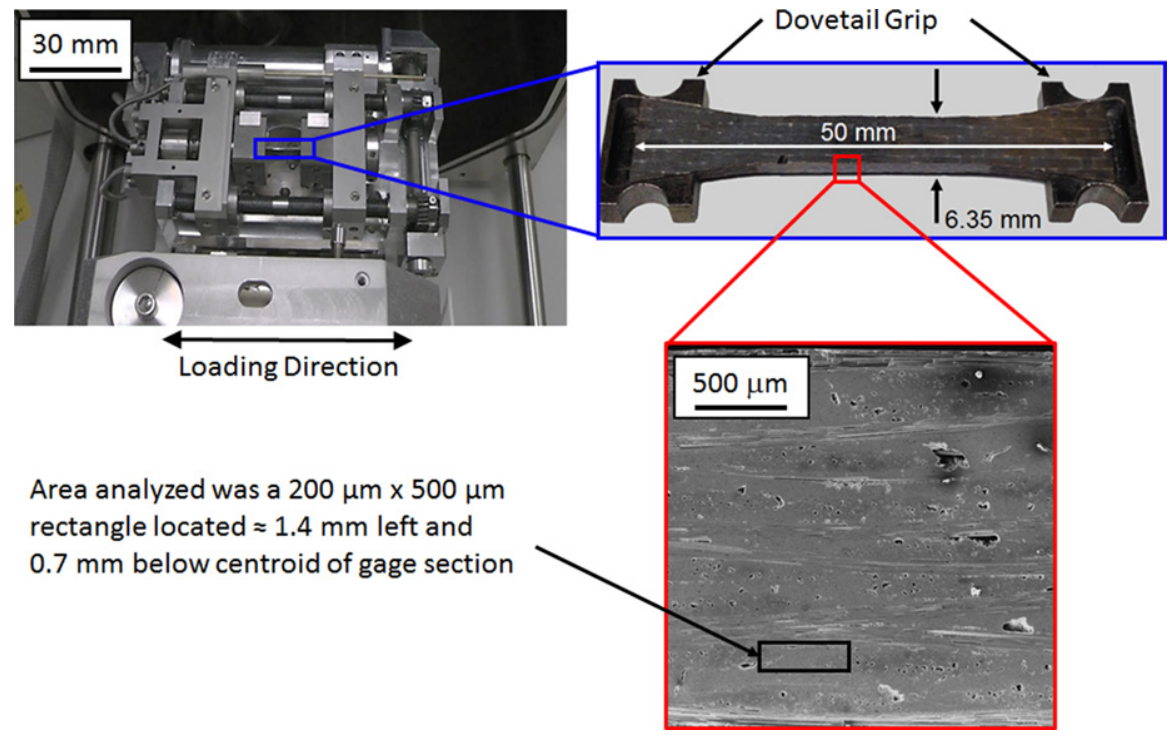

FIGURE 2 Tensile load frame (Kammrath and Weiss) mounted on the door of the SEM. The CMC sample is held between dovetail grips as shown. The red box shows the area on the side of the polished tensile specimen that was investigated in this study. The area investigated with SEM-DIC is enclosed by the black box on the micrograph of the tensile specimen cross-section [Color figure can be viewed at wileyonlinelibrary.com] 
FIGURE 3 CMC cross-section showing the configuration of the microstructure relative to the loading axis. The ten fields of view selected for SEMDIC are denoted by the dotted boxes, and a highlight from one field of view (FOV 2) shows the microstructure with gold nanoparticles deposited for deformation tracking via SEM-DIC. The inset to the left shows a representative sample of the nanoparticles at increased magnification [Color figure can be viewed at wileyonlinelibrary.com]

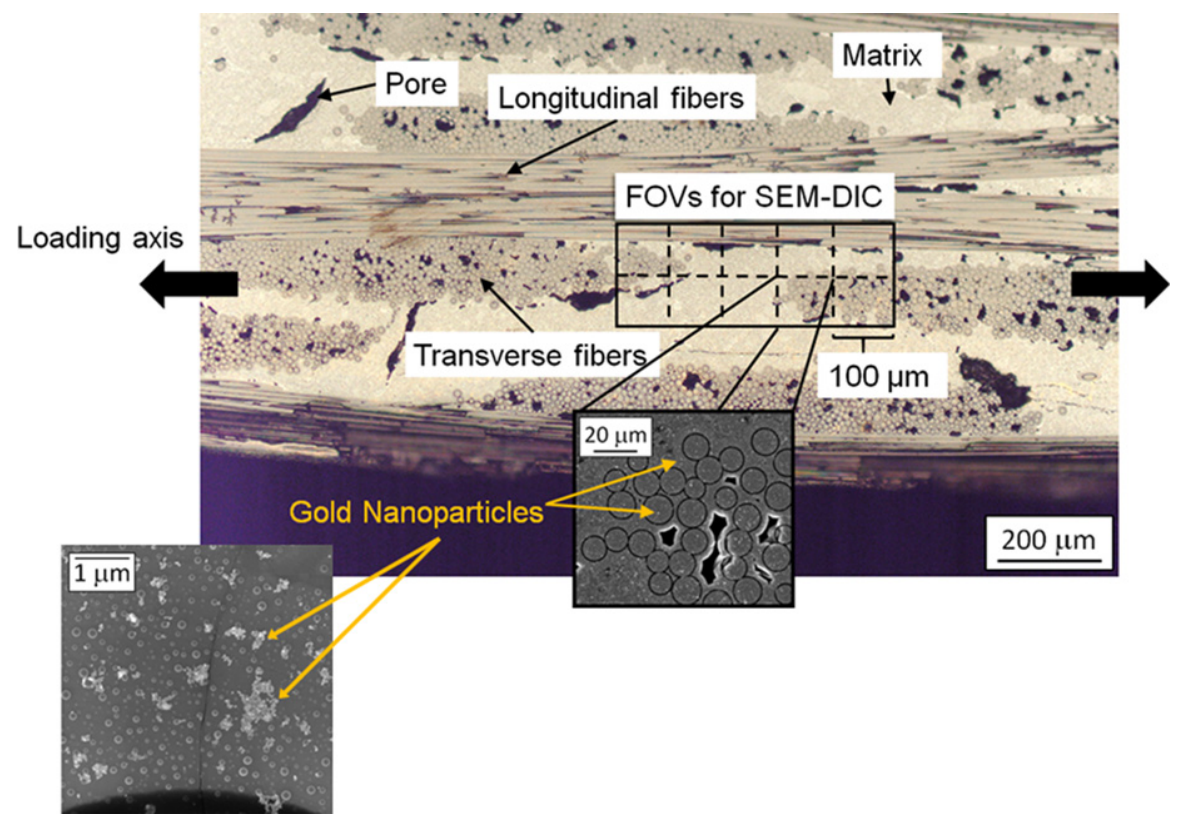

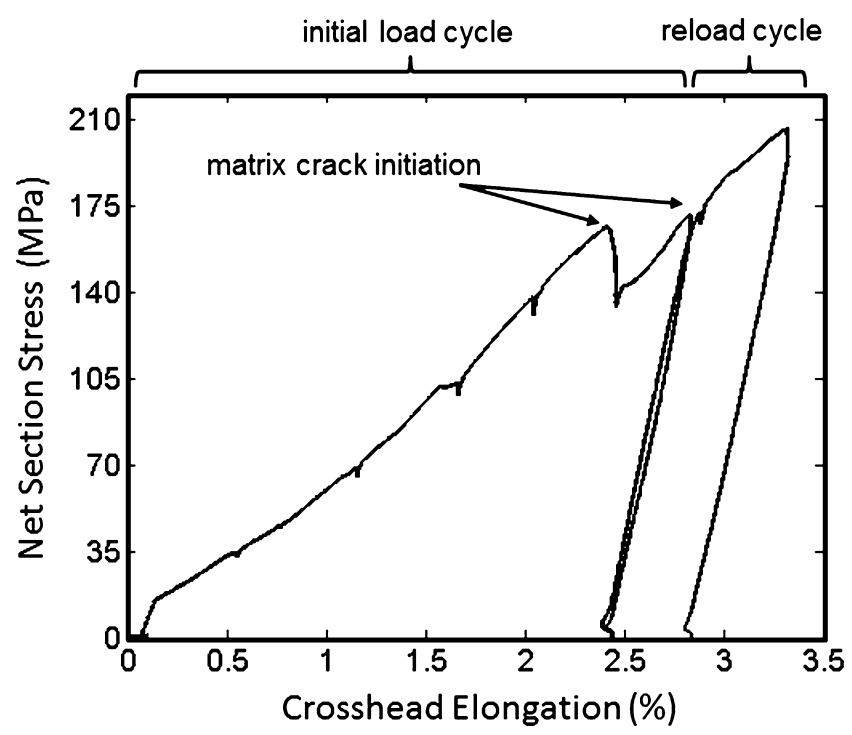

F IGURE 4 The sample was loaded in $35 \mathrm{MPa}$ increments with a hold at each step to allow for image capture for DIC. A small amount of load relaxation took place prior to each DIC measurement. A significant drop in stress occurred between 140 and $175 \mathrm{MPa}$ when matrix cracking occurred in the matrix. After DIC images were recorded at $175 \mathrm{MPa}$, the sample was unloaded to $0 \mathrm{MPa}$ and reloaded to $210 \mathrm{MPa}$ at $35 \mathrm{MPa}$ increments. During this second loading, DIC images were captured at all FOVs and at the location of a nearby matrix crack

was fully unloaded and removed from the load frame. SEM examination of the sample confirmed nearly complete closure of matrix cracks, as shown in the high magnification inset in Figure 3 of a selected matrix crack after unloading.

The sample was returned to the load frame for a third and final loading cycle. For this loading cycle, three AOIs

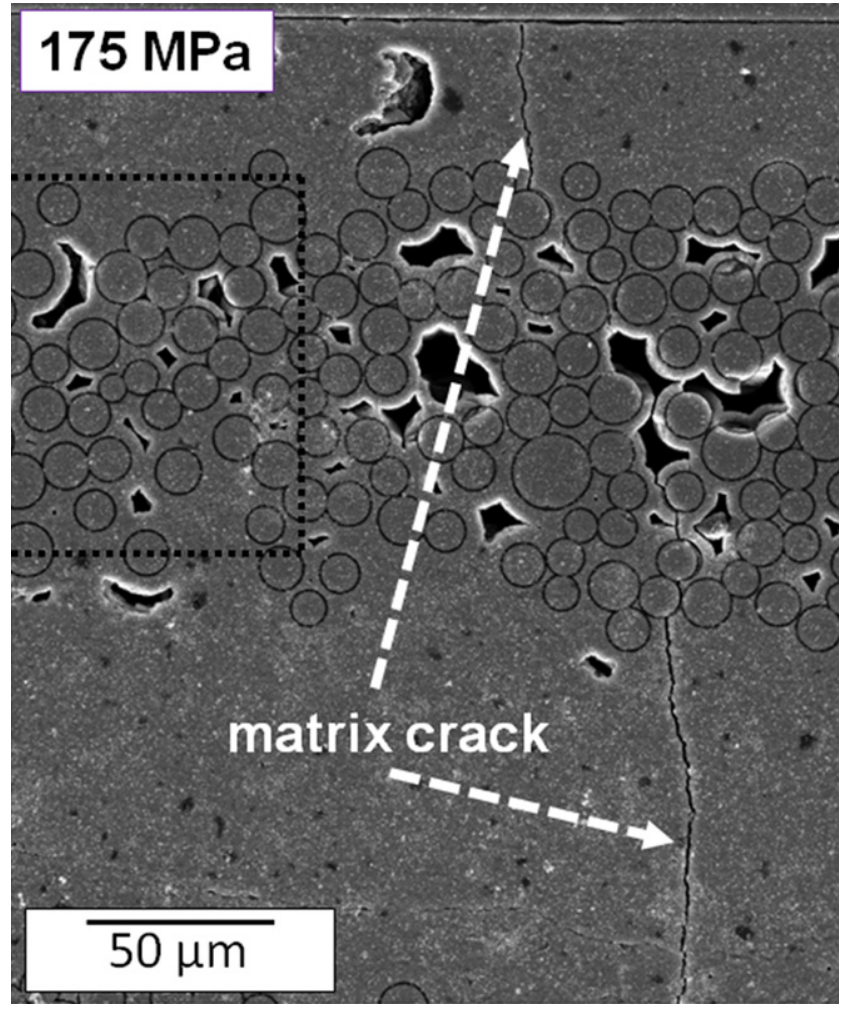

FIGURE 5 A matrix crack developed to the right of the initial AOI during loading between 140 and $175 \mathrm{MPa}$. The dotted black line represents the boundary of FOV1 that is highlighted in Figures 7-9 [Color figure can be viewed at wileyonlinelibrary.com]

containing matrix cracks were selected. Figure 6 shows an approximately $2 \mathrm{~mm} \times 2 \mathrm{~mm}$ area of the sample cross-section containing multiple matrix cracks, captured when the sample was under a far field stress of $210 \mathrm{MPa}$ during the second loading cycle. The three AOIs examined during the 


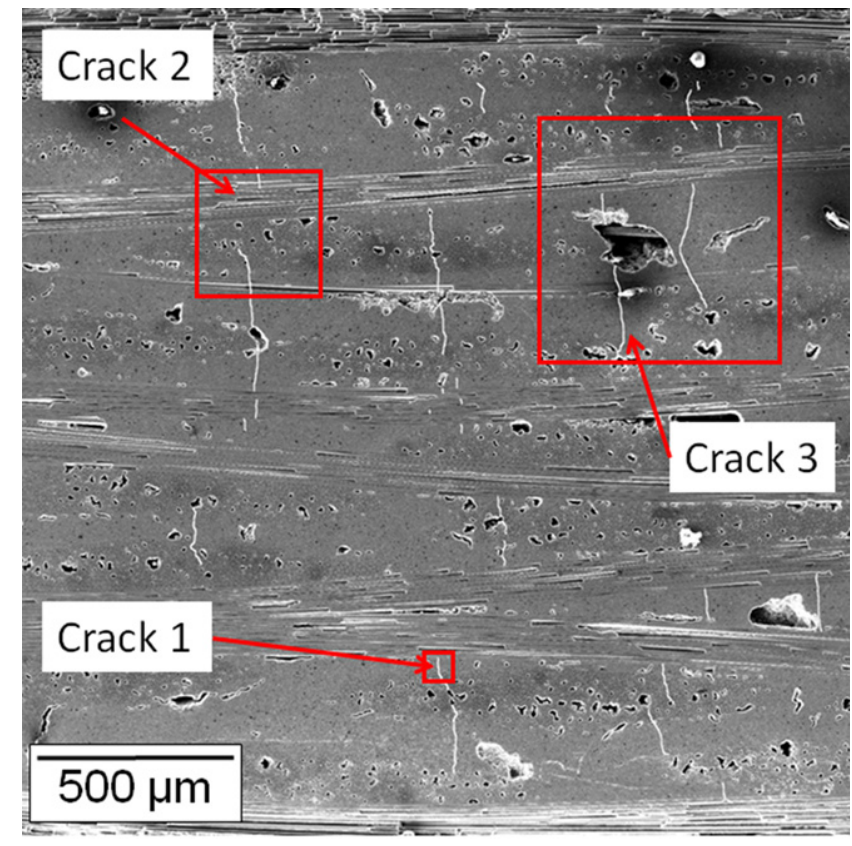

FIGURE 6 Multiple matrix cracks were observed in the gage section at an applied stress of $175 \mathrm{MPa}$. The cracks are highlighted by the superposition of white lines. The three cracks selected for crack opening measurements are highlighted with red boxes [Color figure can be viewed at wileyonlinelibrary.com]

third loading cycle are each outlined by a red box in Figure 6. Micrographs of $10 \mu \mathrm{m} \times 10 \mu \mathrm{m}$ FOVs were captured at three locations along each crack at applied far field stresses of approximately 70, 105, 140, 175, and $210 \mathrm{MPa}$. Larger FOVs $(100-300 \mu \mathrm{m})$ were also captured at far field stresses of approximately 70,140, and $210 \mathrm{MPa}$ to document the location of each $10 \mu \mathrm{m} \times 10 \mu \mathrm{m}$ FOV along each crack. Local matrix crack openings were measured in the smaller $10 \mu \mathrm{m} \times 10 \mu \mathrm{m}$ FOV images using commercial software (Brava! Reader). Matrix crack openings were measured perpendicular to the crack edges at $1 \mu \mathrm{m}$ intervals and an average crack opening was calculated from the measurements made in each $10 \mu \mathrm{m}$ FOV. In some FOVs, both a matrix crack and a crack along the fiber/matrix interface were captured; only the opening of the matrix crack was measured in these cases.

\section{3 | RESULTS AND DISCUSSION}

\section{1 | SEM-DIC observation of damage evolution below the proportional limit}

As shown in Figure 7, the microscale strain fields obtained via SEM-DIC show possible damage initiation at a much lower far field stress than the proportional limit (PL). A PL of $\sim 145 \mathrm{MPa}$ was measured on an EPM-style tensile sample. During the first loading cycle, localized strain occurred at stresses as low as $35 \mathrm{MPa}$, initiating primarily in the BN fiber interface coatings on the $90^{\circ}$ tows. This localized strain, likely in the form of cracking within the coating-fiber-matrix interface, manifested as localizations in the strain fields as shown in Figure 8 (please see PDF for color.) When interpreting these strain fields, it is important to note that the high-intensity, localized strains shown across the crack faces are artifacts of the correlation algorithm applied to material separation and should not be taken as quantitative values. However, these strain localizations are excellent indicators of cracking/damage and can be used to determine where, in relation to the microstructure, damage first occurs. Strain localizations across coating interfaces are attributed to cohesive fracture in the coating and/or delamination of a coating interface. The BN interfaces have a much lower modulus and strength that the $\mathrm{SiC}$ fiber and matrix. These strain localizations were observed in FOVs across the entire AOI, primarily along the interfaces of transverse fibers (fibers coming out of the page and running perpendicular to the loading direction), and were also observed adjacent to pores (FOVs 1 and 2 in Figure 7). Figure 7 shows the increasing amount of strain localization with increasing far field stress for three separate FOVs.

Cracking along individual fiber/matrix interfaces produced small $(<30 \mathrm{~nm})$ interfacial openings that generally grew larger as the globally applied load was increased. Not all interfaces exhibited localization, as microstructural variability resulted in variations of the local stress state. To quantify the opening displacements during the first loading cycle, virtual extensometers (VEs) were applied to the experimentally obtained displacements. The endpoints of each extensometer were positioned (at a minimum) one half of a subset length from the crack front to avoid errors that arise from correlating subsets across a discontinuity in the tracking pattern. The locations of example VEs are shown in six FOVs in Figure 8A-F. The interface openings at each location are shown as a function of the far field stress in Figure $8 \mathrm{G}$. The openings all increased to a maximum value at a far field stress of $140 \mathrm{MPa}$, with some openings decreasing at $175 \mathrm{MPa}$ due to nearby matrix cracking. This observed reduction in interface openings after matrix cracking is consistent with the observed reduction in strain adjacent to the matrix crack in Figure 9. Overall, localized damage was greatest along the portions of the interface oriented perpendicular to the loading direction. It is unclear whether damage to the interface coatings (i) was the precursor to the development of matrix cracks, (ii) provided pathways for matrix crack propagation through $90^{\circ}$ tows, or (iii) reduced the local stress concentration and thereby drove matrix cracks along other pathways. It is possible that each of these occurred. To address this uncertainty, additional testing is needed that captures 


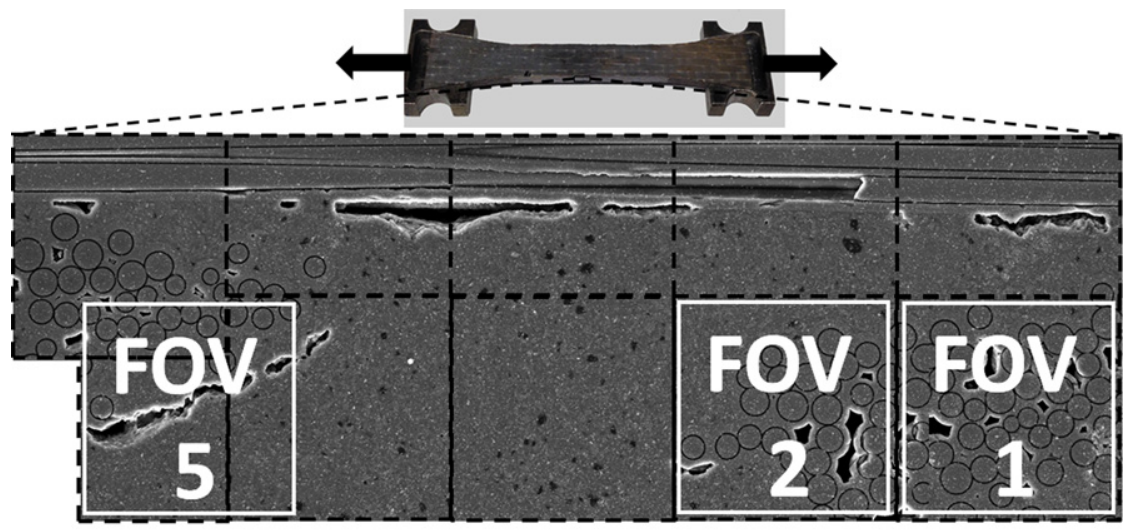

FIGURE 7 Damage accumulation below the PL, indicated by localized elevated strain, is seen in all FOVs. Three FOVs are highlighted here to show damage is observed at far field stresses as low as
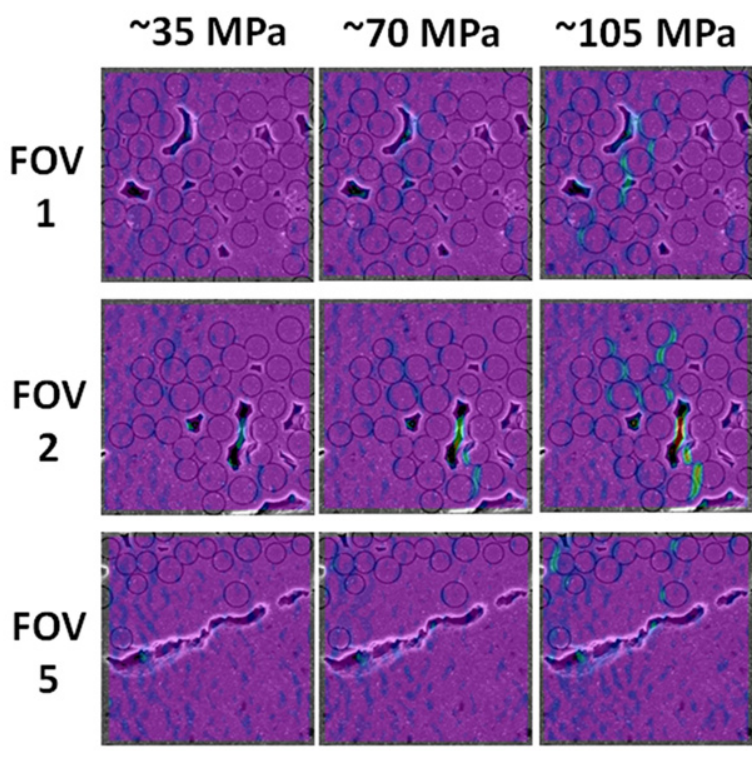

\section{$\varepsilon_{\mathrm{xx}(\mu \varepsilon)}$}

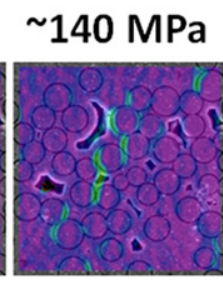

$\Gamma^{9500}$

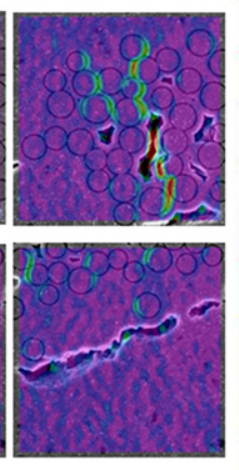

$\sim 70 \mathrm{MPa}$ [Color figure can be viewed at wileyonlinelibrary.com]

crack initiation and propagation in regions where measurements of localized interface damage and opening have been made prior to matrix cracking.

\subsection{Strain relaxation upon introduction of matrix cracking}

Matrix cracking was macroscopically observed as a drop in the applied far-field stress (Figure 4), and simultaneously as a strain relaxation in the microscale strains in FOVs adjacent to matrix cracks (Figure 9). As shown in Figure $9 \mathrm{~A}, \mathrm{~B}$, the strains in the initial AOI relaxed upon the introduction of the matrix crack to the right of the initial AOI. The localized strains in the initial AOI at a globally applied stress of $\sim 140 \mathrm{MPa}$ are shown in Figure 9A, whereas the strain field in the same region following the development of a matrix crack less than $100 \mu \mathrm{m}$ to the right (at a globally applied stress of $\sim 175 \mathrm{MPa}$ ) is shown in Figure 9B. Note that the matrix crack is not shown in Figure 9A, as the matrix crack locations could not be predetermined and the sample cracked approximately $70 \mu \mathrm{m}$ to the right of the originally chosen AOI. The crack in Figure 9B was captured at a globally applied stress of $\sim 175 \mathrm{MPa}$ prior to unloading. The strain magnitudes decreased in the regions adjacent to and to the left of the matrix crack, and strain relaxation became more pronounced closer to the crack.

Strain relaxation in regions adjacent to matrix cracking was due to relief of local stress in the matrix and subsequent load shedding onto the longitudinal fibers that bridge the crack. The length scale over which this local stress reduction occurred is a function of the interfacial shear strength and constituent properties. ${ }^{9}$ The test data in Figures 8 and 9 are, to the best of the authors' knowledge, the 


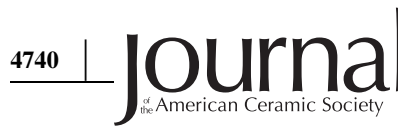
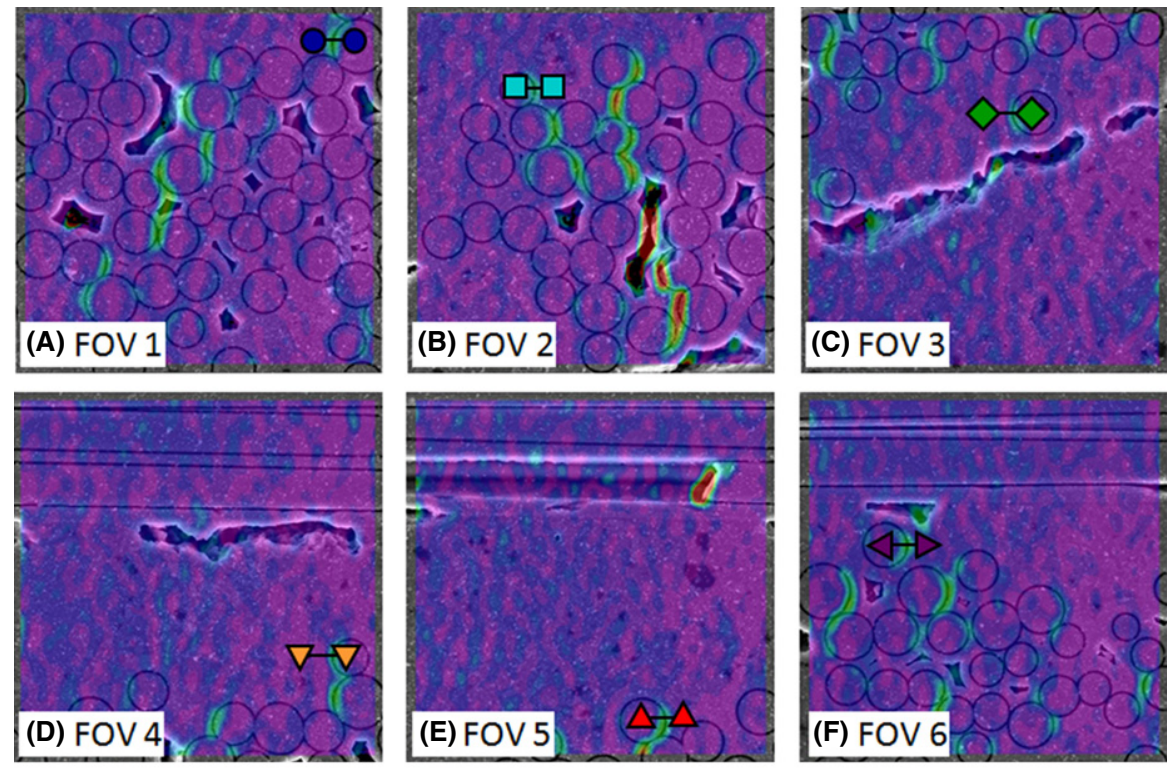

(G)

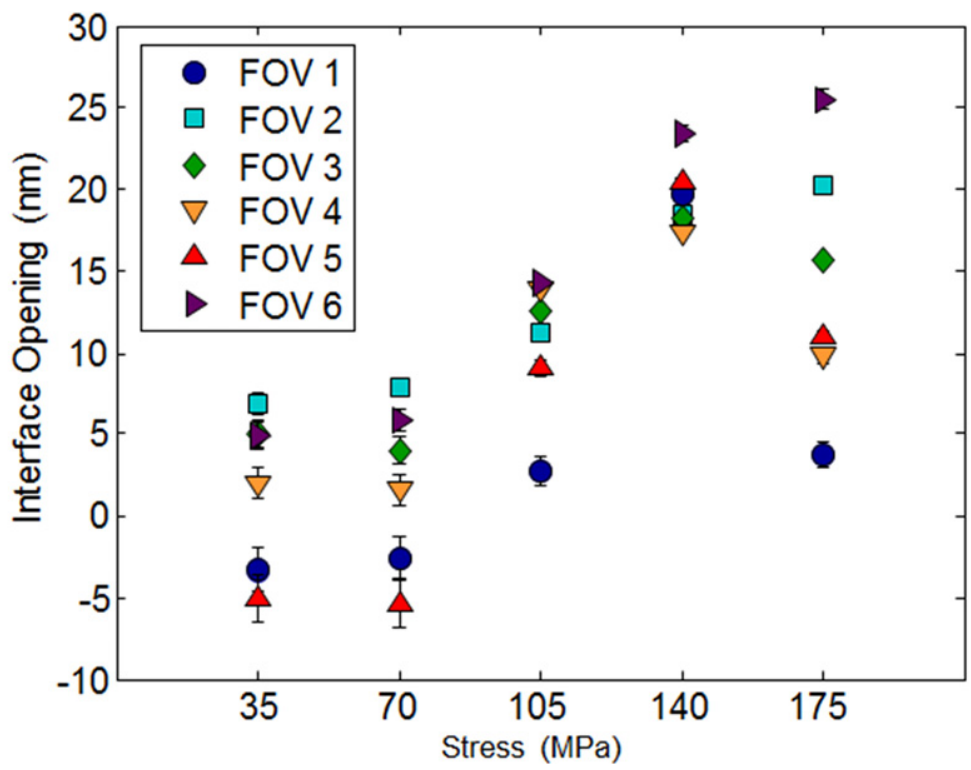

FIGURE 8 Virtual extensometers placed across a fiber interface in six FOVs measure the opening of the interface as a function of stress. All openings increased to a maximum value at a far-field stress of $140 \mathrm{MPa}$ with some openings decreasing at $175 \mathrm{MPa}$ due to nearby matrix cracking. It is unclear whether damage to the interface coatings provided pathways for the later development of matrix cracks, or if interfacial damage reduced the local stress concentration and thereby drove matrix cracks along other pathways. (The images in a-f were captured at $140 \mathrm{MPa}$.) [Color figure can be viewed at wileyonlinelibrary.com] first direct experimental observation of this strain relaxation behavior in CMCs and its dependence upon crack proximity. The ability to experimentally observe this behavior allows future exploration of how the interactions between crack proximity and strain relaxation influences the development of additional matrix cracks. Such experimental observations can be used to validate or challenge existing matrix cracking models and to determine which of these and other factors are significant for incorporation into modeling and lifing predictions.

\section{3 | Enhanced detection of crack propagation}

Application of SEM-DIC allowed for the direct measurement of crack opening displacements through the application of virtual extensometers (VEs) and by the manual examination of high magnification micrographs of cracks. SEM-DIC allowed measurement of openings on the order of tens of nanometers at stresses below the proportional limit. As previously noted, the CODs currently used in modeling efforts are largely calculated estimates. ${ }^{10,34,37,38}$ Few direct measurements of CODs have been made, largely due to experimental difficulties.

Matrix crack formation was evidenced by a load drop between 140 and $175 \mathrm{MPa}$ in the macroscopic stress-strain curve (Figure 4) and in the strain drops adjacent to the crack shown in Figure 9. As discussed earlier, a matrix crack was not captured in the initial AOI of Figure 9. Thus, in order to capture the behavior, upon reloading, of matrix cracks that formed during the first loading to $175 \mathrm{MPa}$ (shown in Figure 9B), the sample was unloaded 
FIGURE 9 Composite images showing (A) the localized strains in the initial AOI prior to matrix cracking at a far field stress of $\sim 140 \mathrm{MPa}$; and (B) the strain field in the same region at a far field stress of

$\sim 175 \mathrm{MPa}$ following introduction of a matrix crack less than $100 \mu \mathrm{m}$ to the right, showing significant relaxation. The red box in (B) outlines the region highlighted in Figure 10 [Color figure can be viewed at wileyonlinelibrary.com]

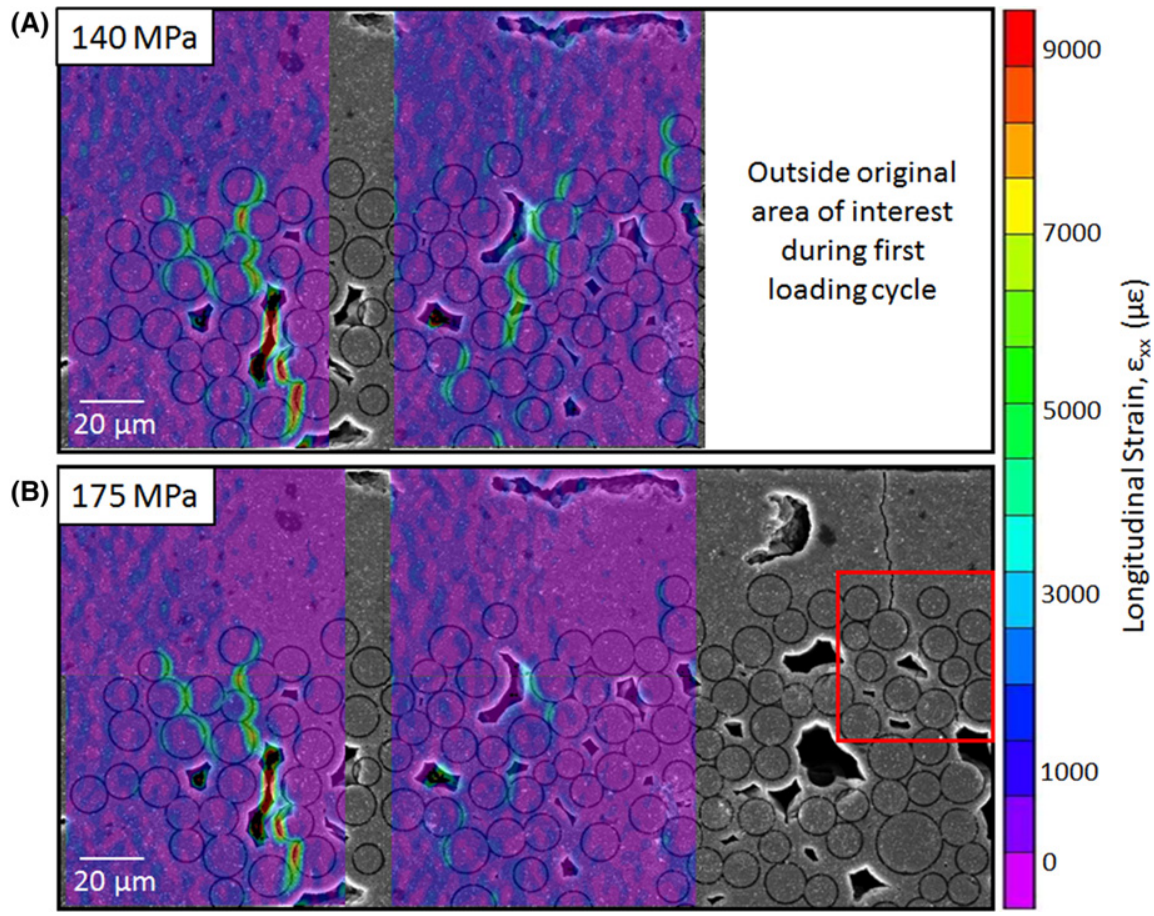

and an adjacent AOI containing the matrix crack was imaged at a nominal stress of $0 \mathrm{MPa}$ to provide a reference image. Strains were then calculated when the sample was reloaded. Upon reloading, this matrix crack that had formed during the first loading to $175 \mathrm{MPa}$ began reopening at stresses as low as $35 \mathrm{MPa}$. The subsequent crack opening/stress relationship that was measured during reloading reflects the behavior of a pre-existing crack.

In general, matrix crack openings increased with increasing applied stress. To measure local crack openings, virtual extensometers (VEs) were placed across the matrix crack from Figure 9 as shown in Figure 10. The crack opening measurements at each VE location were consistent at each extensometer position for each stress increment. Due to the complexity of the microstructure through which the matrix crack traveled, the crack propagated through matrix-rich regions, along fiber interfaces, and between closely spaced fibers. Isolating the matrix crack opening required that VEs not bridge any fiber interfaces where cracking and damage may also be present. That left little crack length within the AOI for crack opening displacement measurements from the SEM-DIC data. For this reason, a third loading of the sample and manual examination of the three separate matrix cracks was performed.

The white lines in Figure 6 highlight the locations of matrix cracks, and the red boxes show the three AOIs, each incorporating a single matrix crack, that were examined during the third loading cycle to evaluate variations in crack opening displacements. The first crack selected, designated Crack 1, was the same crack shown in Figure 9.
This crack was selected to enable comparison of manually measured crack opening displacements to those calculated by SEM-DIC. Figure 11A shows Crack 1, and highlights the three $10 \mu \mathrm{m} \times 10 \mu \mathrm{m}$ FOVs on that crack used to make crack opening measurements during the third loading cycle. Figure 11B,C show the same for Cracks 2 and 3, respectively. The average crack opening displacements for each of the nine FOVs are shown in Figure 12. The smallest crack observed exhibited an increase in COD from $\sim 0.1$ to $0.25 \mu \mathrm{m}$ over the loading range while the largest crack exhibited an increase in COD from $\sim 0.4$ to $1.1 \mu \mathrm{m}$. These values are consistent with the few values available in the literature. Chateau et al. measured CODs for $\mathrm{SiC} / \mathrm{SiC}$ minicomposites using an in-SEM load frame. ${ }^{34}$ They observed variations in COD of $0.2-1.5 \mu \mathrm{m}$ at the highest loads, and larger CODs for cracks having a larger separation distance from neighboring cracks. McDonald et al. measured crack densities as a function of applied stress in a Nicalon ${ }^{\mathrm{TM}}$ (Dow Corning) SiC fiber reinforced glass ceramic. ${ }^{35} \mathrm{COD}$ was calculated, using the measured crack spacings and strain values and a shear lag model, and was found to be $\sim 0.3 \mu \mathrm{m}$ at a stress of $400 \mathrm{MPa}$. Although Morscher reported CODs on the order of $5-15 \mu \mathrm{m}$ for $\mathrm{SiC} / \mathrm{SiC}$ minicomposites under stress-rupture testing, he did not report any functional dependence of COD on load ${ }^{20}$ and the measurements were made under stress-rupture conditions at temperature where fiber creep is a factor. Finally, Bale et al. measured COD as a function of load for a single crack in a $\mathrm{SiC} / \mathrm{SiC}$ minicomposite at $1750^{\circ} \mathrm{C}$ during $\mu$ computed tomography experiments (see supplemental 


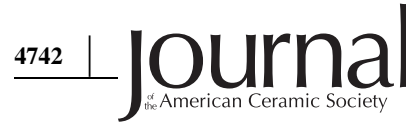
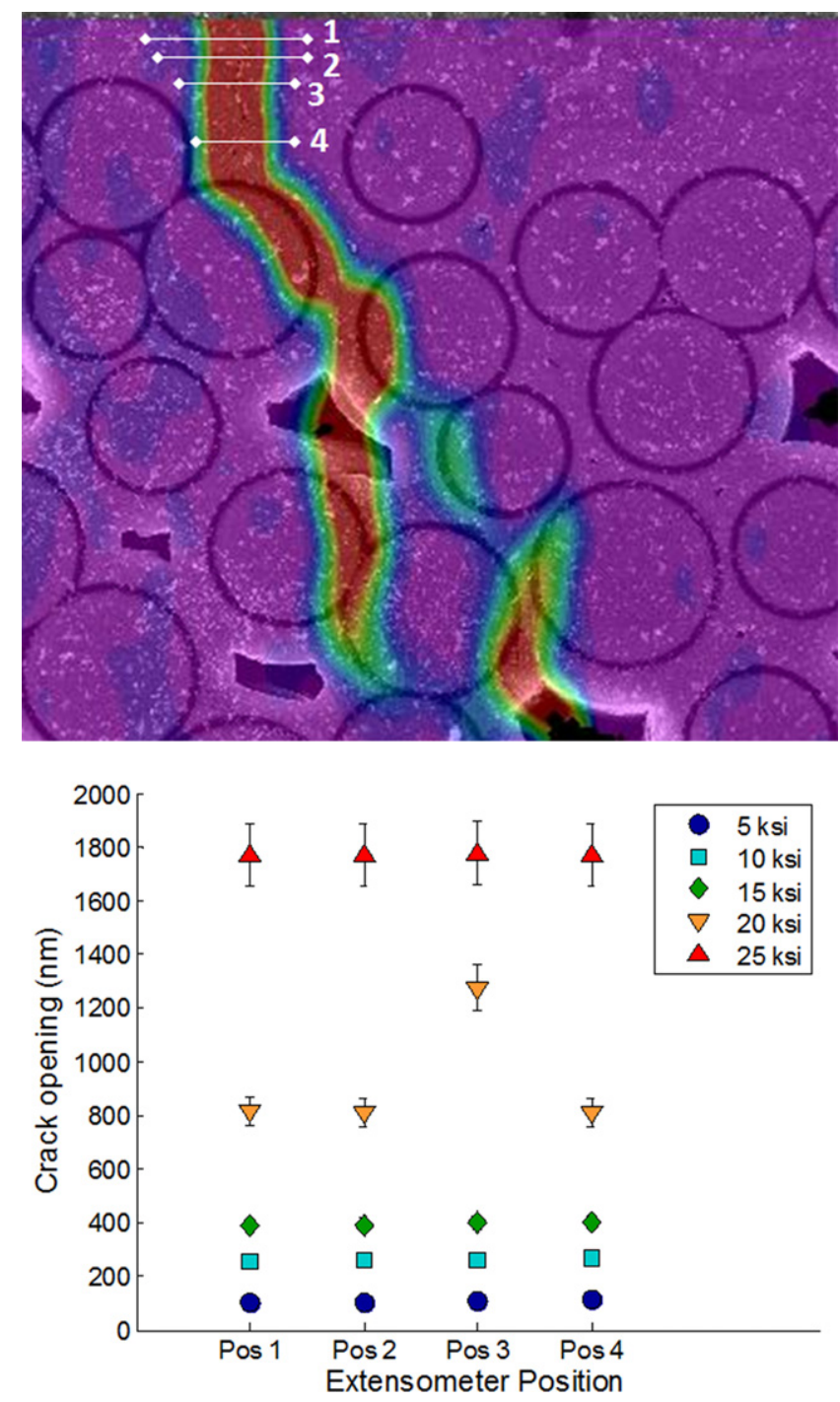

F I G URE 10 The crack opening displacement, measured with virtual extensometers at 4 locations along the matrix crack, increased with increasing far field stress. This region is highlighted in the red box in Figure 9 [Color figure can be viewed at wileyonlinelibrary.com]

materials in Ref. [38]). The resulting CODs range from $20 \mu \mathrm{m}$ at the lowest load to $100 \mu \mathrm{m}$ at the highest load.

While the increase in COD with stress is expected, the variation in COD for a given global stress is not surprising. Woven composites have a complex microstructure with both longitudinal and transverse tows, matrix-rich regions between fabric plies, and areas of overlap in the weave. The local stress state will vary due to these microstructural changes. ${ }^{45}$ The local COD will be affected by the local stress state. The seeming gap in the data where two crack locations show smaller CODs is most likely an artifact of the sampling. A larger sample of crack locations would fill in that gap in the data. The nine FOVs selected do not capture the full variation in CODs due to such factors as local fiber/crack interactions, sampling position relative to the crack tip, and subsurface differences in crack orientation and bridging that are not visible at the surface.

In Figure 12, the average COD increases linearly with global applied stress for all nine FOVS evaluated. This is in contrast to matrix crack models that predict COD following the square of the stress, ${ }^{9}$ however, the discrepancy may be explained by model assumptions that are not applicable to the present study. The model in Ref. [9] was developed for a unidirectional composite with a fully debonded interface and a uniform opening pressure along the crack length. The crack opening is a function of the closing tractions applied by the bridging fibers and varies along the crack length. Indeed, the authors of Ref. [9] state that a rigorous analytic solution for COD cannot be obtained. To get an analytic solution for their analysis, they assumed that for small cracks the COD profile of a crack subjected to a non-uniform bridging traction profile would not differ from the profile of a crack subjected to a uniform bridging traction profile. The parabolic COD versus stress relationship derived comes directly from that assumption and provides the asymptotic value of equilibrium separation where full crack face separation has occurred and the net force in the intact fibers bridging the crack exactly balances the global applied force. A more generalized form of the analysis in Ref. [9] shows a parabolic relationship between COD and the bridging tractions, not the global applied stress. Unlike the unidirectional composite modeled in, ${ }^{9}$ the CMC in this study has a woven fiber architecture. The woven architecture leads to local stress variations that will influence the crack behavior and provides non-uniform bridging along the crack length.

The mechanisms of interfacial debonding, frictional sliding, and interfacial damage will also influence COD. CODs measured at Crack 1 Location 1 using VEs during the second loading cycle $(\sim 1.8 \mu \mathrm{m}$ in Figure 10$)$ were higher than the CODs measured manually during the third loading cycle $(\sim 1.0 \mu \mathrm{m}$ in Figure 13). This observation, and the linear COD relationship, can be attributed to sample unloading/reloading and the progression of damage due to the load cycling. Damage, in the form of additional matrix cracks and interface debonding, progresses in CMCs as the load is increased. Unloading further damages the interface through frictional sliding and wear. Recall that during the first loading cycle, the sample was stressed to $175 \mathrm{MPa}$. At this point, the sample was unloaded to capture baseline images of a matrix crack. The sample was then reloaded and subjected to a maximum stress of $210 \mathrm{MPa}$. During this loading cycle, there was most likely an accumulation of new damage at these higher stresses. As the maximum stress during the third loading cycle was the same as the second cycle, no matrix cracks developed or extended. During this load cycling, fibers bridging the crack would have experienced sliding and wear adjacent to the cracks, 

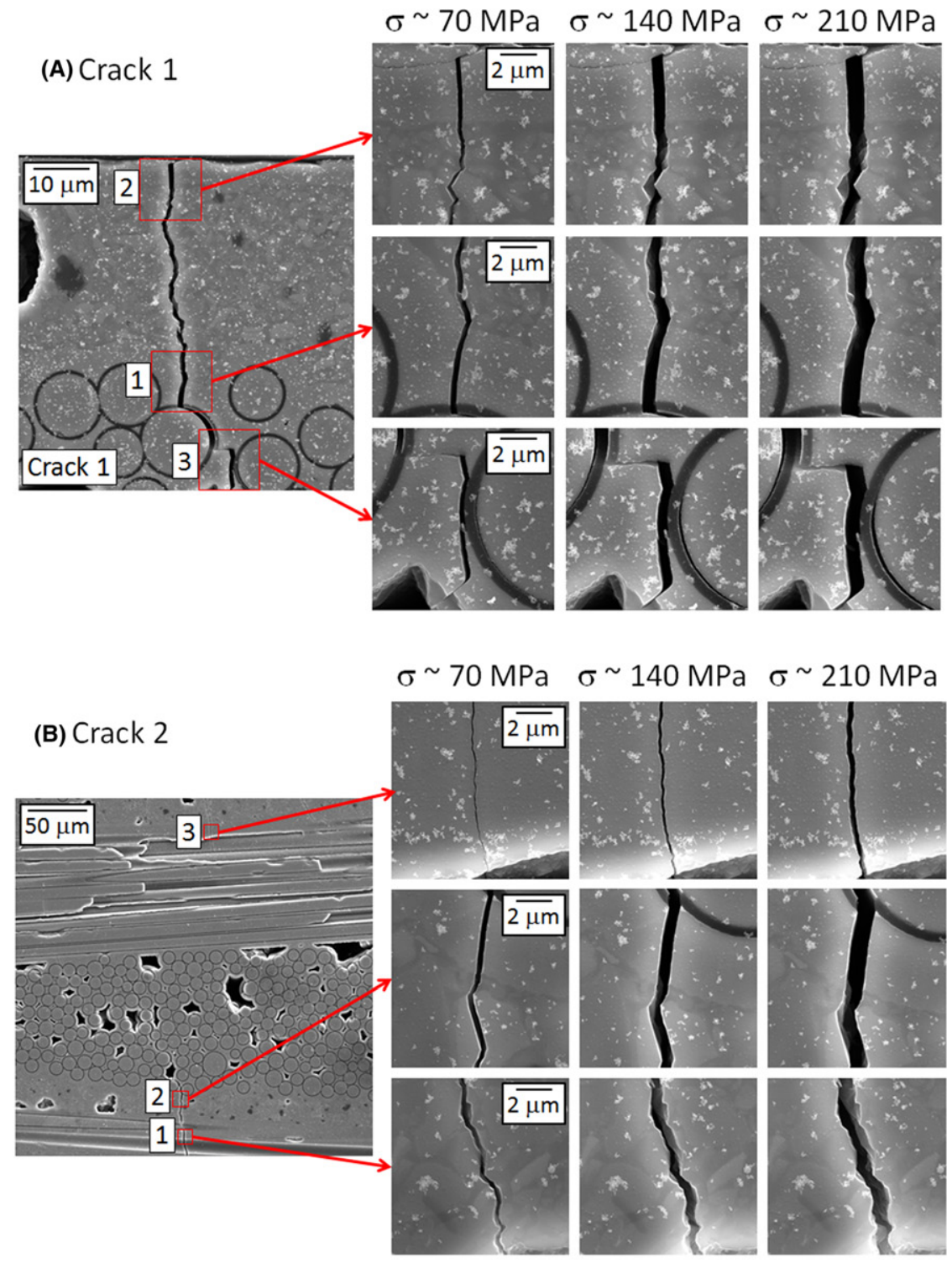

FIGURE 11 Three locations along three cracks were selected for crack opening measurements. For each crack shown in this figure the left image shows the boxed portion of the microstructure from Figure 6 and the images to the right show the progression of crack opening with far field stress for each FOV used to measure crack opening. Crack 1 , shown in (A), is the same matrix crack observed in the SEM-DIC work above. Crack 2 is shown in (B), and crack 3 is shown in (C) [Color figure can be viewed at wileyonlinelibrary.com]

\section{$\sigma \sim 70 \mathrm{MPa} \quad \sigma \sim 140 \mathrm{MPa}$}

\section{(C) Crack 3}

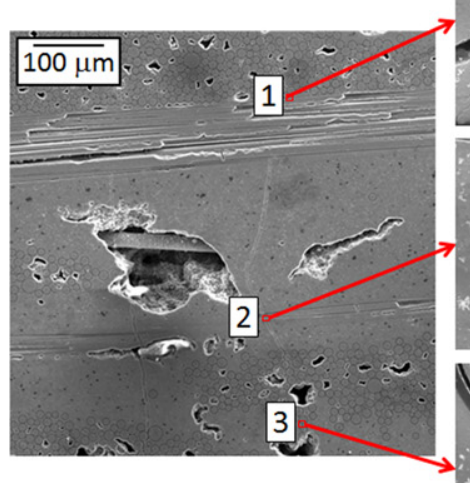

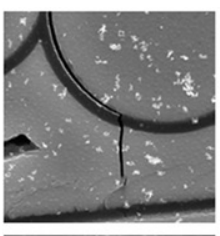
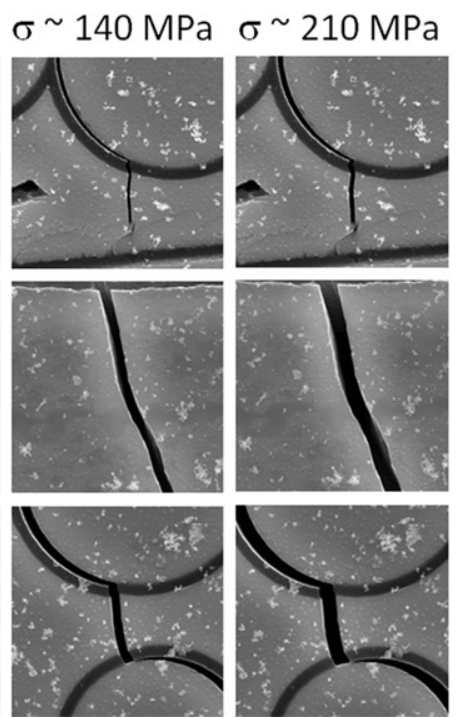
${ }^{\mathrm{vw}} \perp$ journal

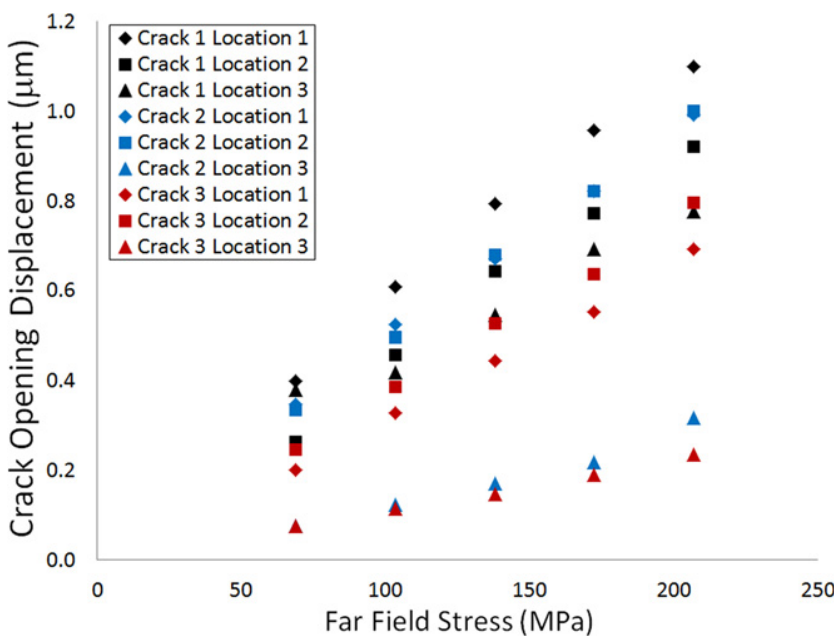

F IGURE 12 For all nine FOVs sampled, matrix crack opening increased with increasing far field stress with the largest initial crack openings showing the largest increase in opening with stress [Color figure can be viewed at wileyonlinelibrary.com]

as well as additional debonding. The load sharing between the fibers and matrix was altered by these interface changes contributing to the observed reduction in crack opening and linear COD/stress relationship.

Most models for matrix cracking incorporate a similar analysis to Ref. [9] and show reasonable agreement with experimentally measured crack densities and stress/strain behavior after fitting for interfacial shear stress and other constituent parameters. In a recent study by Chateau et al. COD data measured during tensile loading of $\mathrm{SiC} / \mathrm{SiC}$ minicomposites were fit with a polynomial regression forcing a parabolic relationship between COD and applied force. ${ }^{34}$ The fit, for data from five cracks selected as relatively isolated from neighboring cracks, resulted in a large range of interfacial parameters. The large range of values were in general agreement with constituent properties, however, the variation could also indicate the need for a better model of the stress dependence of COD. These results, and those of this study, suggest that use of models describing the functional relationship between COD and global stress in either analysis of experimental data or in environmental modeling should be approached with full knowledge of the applicability of initial models assumptions.

No crack passed fully through the cross-section of the gage section, indicating that no crack was uniformly open across the composite cross-section as is often assumed in cracking models of CMCs. This was the case even at the peak far field stress of $210 \mathrm{MPa}, 50 \%$ above the $0.005 \%$ offset proportional limit stress of $145 \mathrm{MPa}$. This is consistent with other observations in woven $\mathrm{CMCs}$ where multiple matrix cracks that are not through-cracks form and grow. ${ }^{29-33,46}$ Under both monotonic and cyclic loading, these cracks eventually link up to form through-cracks. For
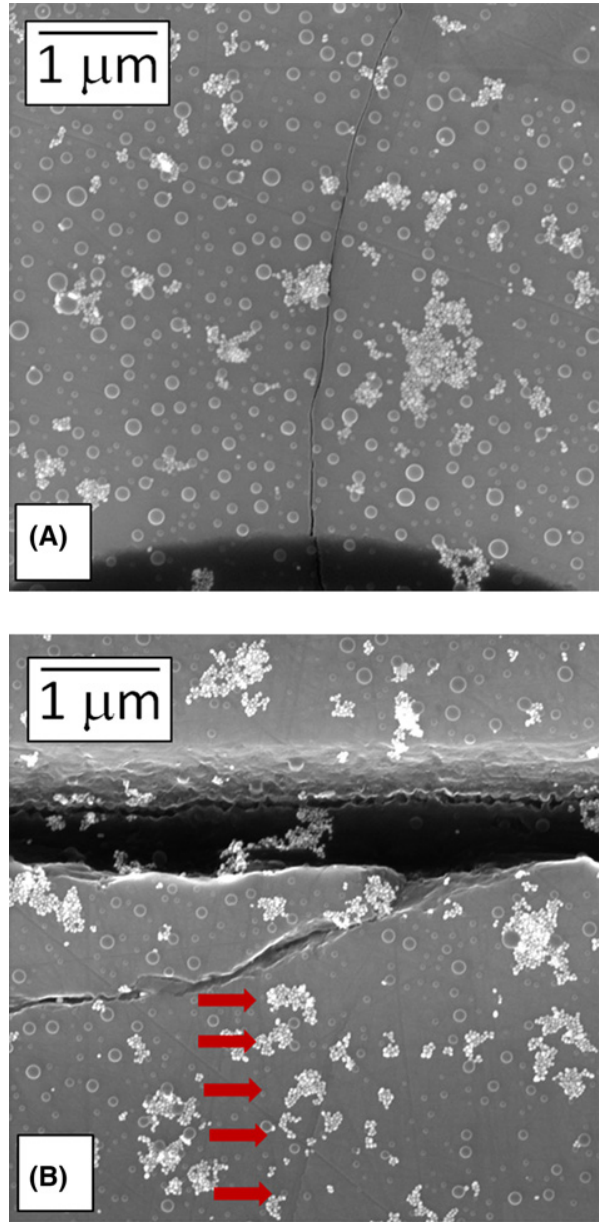

FIGURE 13 (A), Upon removal from the load frame, the crack opening is $\sim 10 \mathrm{~nm}$ immediately adjacent to the transverse fibers and (B), fully closed adjacent to the longitudinal fibers. Arrows are added to show the crack path; the nanoparticles were used to identify the location of the crack [Color figure can be viewed at wileyonlinelibrary.com]

monotonic loading, this crack linking takes place at stresses approaching the ultimate strength $29,46,47$ but for cyclic loading it is not clear when such linking takes place. This finding has important implications for life modeling in CMCs. Modeling cracks as through-cracks at low stresses under monotonic loading, or from the beginning of cyclic loading, can obscure the importance of oxidation mechanisms that are active in actual CMC cracking conditions.

One final observation regarding crack opening displacement further highlights the utility of the SEM-DIC experimental method for crack detection. Crack detection after the load has been removed is extremely difficult, especially in these slurry-cast composites where a residual compressive stress acts to close cracks on unloading. ${ }^{29,30,33}$ Several measurements included in this study were made after the sample had been removed from and then returned to the load frame. There was little residual crack opening observable after unloading and removal from the load frame. 
Cracks were only found through the use of the nanoparticle tracking pattern and comparison with the loaded images (Figure 13). Without the random and dense distribution of nanoparticles that had been chemically attached to the surface, finding the cracks, particularly in the matrix region, would have been improbable due to their extremely small size. Using the nanoparticles and their relative locations in the loaded images to track their unloaded position, the crack opening displacements upon unloading were measured to be on the order of 0-10 nm.

\subsection{Relevance to oxidation modeling}

Current oxidation models focus on the intermediate temperature regime where pest oxidation dominates $\left(700^{\circ} \mathrm{C}\right.$ $1000^{\circ} \mathrm{C}$ ), when matrix cracks allow environmental ingress at stress levels above the proportional limit. ${ }^{23-28}$ These models all treat matrix cracks as through-thickness cracks intersecting the surfaces and providing pathways for environmental ingress. These assumptions of uniformly open through-cracks for all loading conditions and fiber architectures may predict more aggressive oxidation in many cases. In this study, COD varied by a factor of 10 . During oxidation, crack lengths with smaller CODs may inhibit oxygen ingress into the interior of the composite. These regions of smaller COD may also close up more quickly due to formation of oxide scale on the crack faces. Additionally, the absence of through-cracks observed in this study, and consistent with published literature for complex fiber geometries, suggests oxygen will not penetrate far into the composite. The models also make the diffusion rate (gas diffusivity) of oxygen within these through-thickness cracks a function of the crack opening displacement. ${ }^{26}$ As such, a model assuming a uniform COD could overestimate the rate of oxygen transfer within a real composite exhibiting variation in COD. The cracking behavior observed in this study suggests current oxidation models could overestimate composite degradation due to oxidation, and that additional experimental data are needed for model training, validation, and calibration. This study was performed at room temperature and additional studies at elevated temperature are needed to capture any stress relaxation and embrittlement effects on crack opening and progression.

\subsection{Sources of error and experimental limitations}

As with any experimental effort, there are potential sources of errors and experimental limitations that should be discussed. The uncertainty in the SEM-DIC crack opening measurements was determined through rigid body translations. During a pre-test calibration procedure, the sample was translated known distances. Displacements were measured for each translation to determine the functional relationship between displacement error and measured displacement. The uncertainty for displacements of $\sim 1 \mu \mathrm{m}$, on the order of the CODs measured in this study, was determined to be approximately $7 \%$. Uncertainty for smaller displacements, including the interface openings, was less. The uncertainty of the manual COD measurements was determined by calibration of known lengths, and through assessment of the repeatability error by measuring the same feature multiple times. Through uncertainty propagation, the error in the manual measurements was determined to be approximately $1 \%$.

In terms of experimental limitations, the analysis in this work was performed on surface deformations and observations. It is well-known that there are subsurface effects and that cracks propagate in a non-uniform and unpredictable manner underneath the surface. CODs below the surface may differ from those observed on the surface, but the trends of increasing crack opening with increasing load will remain. Given the scatter in CODs measured in the nine observed fields of view, subsurface variation is expected to be on the same order of magnitude. Extension of this work by combining methods discussed herein with new methods of in-situ, subsurface characterization, like computed tomography, will shed more light on the limitations of surface only measurements. Another limitation of note is that the analyses were performed on relatively limited fields of view. The limited field of view prevented direct observation of initial matrix crack initiation. However, direct evidence of certain behaviors, for example strain relaxation and CODs consistent with manual measurements, were captured, indicating the power of this experimental approach in investigating these complex materials.

\section{4 | CONCLUSIONS}

In-SEM tensile tests coupled with SEM-DIC were used to characterize and quantify damage evolution in a woven slurry-cast, melt infiltrated $\mathrm{SiC} / \mathrm{SiC}$. The following findings resulted from this work:

1. The occurrence of matrix cracking resulted in a drop in the applied far-field stress and strain relaxation in the microscale strains regions of cracking. Strain relaxation in adjacent regions was attributed to the relief of local stress in the matrix and subsequent load shedding onto the longitudinal fibers that bridge the crack. This work represents, to the best of the authors' knowledge, the first direct experimental observation of this strain relaxation behavior in $\mathrm{CMCs}$ and its dependence upon crack proximity. 
2. Crack openings increased linearly with increasing applied stress. Variation in the measured CODs was consistent with the limited COD data available in the literature.

3. No crack was found to pass fully through the cross-section of the gage section, indicating that the modeling assumptions of uniformly open cracks across the composite cross-section may not be valid. Modeling cracks as through-cracks for all loading conditions and all fiber architectures can inaccurately represent many actual CMC cracking conditions and may obscure the importance of oxidation mechanisms.

4. The SEM-DIC experimental method was demonstrated to be a powerful means for damage identification and quantification in CMCs at stresses well below the proportional limit.

\section{ACKNOWLEDGMENTS}

We gratefully acknowledge the financial support of NASA Glenn Research Center (F039383-079382), and the material provided by them for these investigations.

\section{REFERENCES}

1. Brewer D. HSR/EPM combustor materials development program. Mater Sci Eng, A. 1999;A261:284-291.

2. Brewer D, Ojard G, Gibler M. Ceramic matrix composite combustor liner rig test, ASME Paper 2000-GT-0670 in Proceedings of ASME Turbo Expo 2000. Munich, Germany: ASME; 2000.

3. Corman GS, Luthra K. Silicon Melt Infiltrated Ceramic Composites (HiPerComp). In: Bansal N, eds. Handbook of Ceramic Composites. NY: Kluwer Academic; 2005:99-115.

4. DiCarlo JA, Yun HM, Morscher GN, Bhatt RT. SiC/SiC composites for $1200^{\circ} \mathrm{C}$ and above, NASA/TM-213048, November; 2004.

5. Spriet P. CMC Applications to Gas Turbines. In: Bansal N, Lamon J, eds. Ceramic Matrix Composites. NJ: American Ceramic Society, Wiley; 2015:593-608.

6. DiCarlo JA, Yun HM, Morscher GN, Bhatt RT. Progress in SiC/ $\mathrm{SiC}$ development for gas turbine hot-section components under NASA EPM and UEET programs, ASME Paper GT-2002-30461, Proceedings of ASME Turbo Expo 2002. Amsterdam, The Netherlands; 2002.

7. Morscher GN, Pujar VV. Melt-infiltrated SiC composites for gas turbine engine applications, ASME Paper GT-2004-53196, Proceedings of ASME Turbo Expo 2004. Vienna, Austria; 2004.

8. Aveston J, Cooper GA, Kelly A. Single and Multiple Fracture. In: The Properties of Fiber Composites, Conference Proceedings of the National Physical Laboratory. Surrey, England: IPC Science and Technology Press Ltd; 1971:15-26.

9. Marshall DB, Cox BN, Evans AG. The mechanics of matrix cracking in brittle matrix fiber composites. Acta Metall Mater. 1985;33:2013-2021.

10. Marshall DB, Evans AG. Failure mechanisms in ceramic fiber/ceramic matrix composites. J Am Ceram Soc. 1985;68:225-231.

11. Budiansky B, Hutchinson JW, Evans AG. Matrix fracture in fiberreinforced composites. J Mech Phys Solids. 1986;34:167-189.
12. Evans AG, Marshall DB. The mechanical behavior of ceramic matrix composites. Acta Metall Mater. 1989;37:2567-2583.

13. Kerans RJ, Hay RS, Pagano NJ, Parthasarathy TA. The role of the fiber-matrix interface in ceramic composites. Ceramic Bulletin. 1989;68:429-442.

14. Morscher GN, Hurst J, Brewer D. Intermediate-temperature stress rupture of a woven Hi-nicalon, BN-interphase, SiC-matrix composite in air. J Am Ceram Soc. 2000;83:1441-1449.

15. Morscher GN, Cawley JD. Intermediate temperature strength degradation in $\mathrm{SiC} / \mathrm{SiC}$ composites. J. Euro. Ceram. Soc. 2002;22:2777-2787.

16. Naslain R, Guette A, Rebillat F, et al. Oxidation mechanisms and kinetics of SiC-matrix composites and their constituents. J. Mat. Sci. 2004;39:7303-7316.

17. Evans AG, Zok FW, McMeeking RM, Du ZZ. Models of hightemperature, environmentally assisted embrittlement in ceramicmatrix composites. J Am Ceram Soc. 1996;79:2345-2352.

18. Lin HT, Becher PF. Effect of fiber coating on lifetime of Nicalon fiber-silicon carbide composites in air. J. Mater. Sci. Eng. A. 1997;231:143-150.

19. Morscher GN, Bryant DR, Tressler RE. Environmental durability of BN-based interphases (for $\mathrm{SiC}_{\mathrm{f}} / \mathrm{SiC}_{\mathrm{m}}$ Composites) in $\mathrm{H}_{2} \mathrm{O}$ containing atmospheres at intermediate temperature. Ceram. Eng. Sci. Pro. 1997;18:525-534.

20. Morscher GN. Tensile stress rupture of $\mathrm{SiC}_{\mathrm{f}} / \mathrm{SiC}_{\mathrm{m}}$ minicomposites with carbon and boron nitride interphases at elevated temperatures in air. J Am Ceram Soc. 1997;80:2029-2042.

21. Ruggles-Wrenn MB, Jones TP. Tension-compression fatigue of a $\mathrm{SiC} / \mathrm{SiC}$ ceramic matrix composite at $1200^{\circ} \mathrm{C}$ in air and in steam. Int J Fatigue. 2013;47:154-160.

22. Ruggles-Wrenn MB, Delapasse J, Chamberlain AL, Lane JE, Cook TS. Fatigue behavior of a Hi-Nicalon ${ }^{\mathrm{TM}} / \mathrm{SiC}-\mathrm{B}_{4} \mathrm{C}$ composite at $1200^{\circ} \mathrm{C}$ in air and in steam. J. Mater. Sci. Eng. A. 2012;534:119-128.

23. Parthasarathy TA, Przybyla CP, Hay RS, Cinibulk MK. Modeling environmental degradation of $\mathrm{SiC}$-fiber reinforced CMCs, Proceedings of the 39th Annual Conference on Composites, Materials, and Structures. Cocoa Beach/Cape Canaveral, Florida: USACA; 2015.

24. Xu W, Zok FW, McMeeking RM. Model of oxidation-induced fiber fracture in $\mathrm{SiC} / \mathrm{SiC}$ composites. $J$ Am Ceram Soc. 2014;97:3676-3683.

25. Sullivan RM. Time-dependent stress rupture strength of Hi-Nicalon fiber-reinforced silicon carbide composites at intermediate temperatures. J. Euro. Ceram. Soc. 2016;36:1885-1892.

26. Forio P, Lavaire F, Lamon J. Delayed failure at intermediate temperatures $\left(600-700^{\circ} \mathrm{C}\right)$ in air in silicon carbide multifilament tows. J Am Ceram Soc. 2004;87:888-893.

27. Gauthier W, Pailler F, Lamon J, Pailler R. Oxidation of silicon carbide fibers during static fatigue in air at intermediate temperatures. J Am Ceram Soc. 2009;92:2067-2073.

28. Gauthier W, Lamon J. Delayed failure of Hi-Nicalon and Hi-Nicalon $\mathrm{S}$ multifilament tows and single filaments at intermediate temperatures $\left(500^{\circ} \mathrm{C}-800^{\circ} \mathrm{C}\right)$. J Am Ceram Soc. 2009;92:702-709.

29. Morscher GN. Stress-dependent matrix cracking in 2D woven SiC-fiber reinforced melt-infiltrated $\mathrm{SiC}$ matrix composites. Compos Sci Technol. 2004;64:1311-1319.

30. Morscher GN, Ojard G, Miller R, et al. Tensile creep and fatigue of Sylramic-iBN melt-infiltrated $\mathrm{SiC}$ matrix composites: retained 
properties, damage development, and failure mechanisms. Compos Sci Technol. 2008;68:3305-3313.

31. Sujidkul T, Smith CE, Ma Z, Morscher GN, Xia Z. Correlating electrical resistance change with mechanical damage in woven $\mathrm{SiC} / \mathrm{SiC}$ composites: experiment and modeling. J Am Ceram Soc. 2014;97:2936-2942.

32. Lamon J. A micro-mechanics based approach to the mechanical behavior of brittle-matrix composites. Compos Sci Technol. 2001;61:2259-2272.

33. Morscher GN, DiCarlo JA, Kiser JD, Yun HM. Effects of fiber architecture on matrix cracking for melt-infiltrated $\mathrm{SiC} / \mathrm{SiC}$ composites. Int J Appl Ceram Technol. 2010;7:276-290.

34. Chateau C, Gélébart L, Bornert M, Crépin J, Caldemaison D, Sauder C. Modeling of damage in unidirectional ceramic matrix composites and multi-scale experimental validation on third generation SiC/SiC minicomposites. J. Mech. Phys. Sol. 2014;63:298-319.

35. McDonald KR, Dryden JR, Zok FW. Effects of matrix cracks on the thermal diffusivity of a fiber-reinforced ceramic composite. $J$ Am Ceram Soc. 2001;84:2015-2021.

36. Bhatt RT, Fox D, Smith C. Creep behavior and durability of cracked CMC, Proceedings of the 39th Annual Conference on Composites, Materials, and Structures. Cocoa Beach/Cape Canaveral, Florida: USACA; 2015.

37. Tracy J, Daly S, Sevener K. Multiscale damage characterization in continuous fiber ceramic matrix composites using digital image correlation. J Mater Sci. 2015;50:5286-5299.

38. Bale HA, Haboub A, MacDowell AA, et al. Real-time quantitative imaging of failure events in materials under load at temperatures above $1600^{\circ}$ C. Nat Mater. 2013;12:S1-S8. https://doi.org/ 10.1038/nmat3497.

39. DiCarlo JA, Bansal NP. Fabrication routes for continuous fiberreinforced ceramic composites (CFCC), NASA TM-208819, November; 1998.

40. Schreier H, Orteu JJ, Sutton MA. Image Correlation for Shape, Motion and Deformation Measurements: Basic Concepts. New
York NY: Theory and Applications. Springer Science + Business Media; 2009.

41. Sutton MA, Li N, Joy DC, Reynolds AP, Li X. Scanning electron microscopy for quantitative small and large deformation measurements Part I: SEM imaging at magnifications from 200 to 10,000. Exp Mech. 2007;47:775-787.

42. Sutton MA, Li N, Garcia D, et al. Scanning electron microscopy for quantitative small and large deformation measurements Part II: experimental validation for magnifications from 200 to 10,000. Exp Mech. 2007;47:789-804.

43. Kammers AD, Daly S. Digital image correlation under scanning electron microscopy: methodology and validation. Exp Mech. 2013;53:1743-1761.

44. Kammers AD, Daly S. Self-assembled nanoparticle surface patterning for improved digital image correlation in a scanning electron microscope. Exp Mech. 2013;53:1333-1341.

45. Gowayed Y, Ojard G, Santhosh U, Jefferson G. Modeling of crack density in ceramic matrix composites. J. Comp. Mater. 2015;49:2285-2294.

46. Rao MP, Pantiuk M, Charalambides PG. Initiation of matrix cracking in woven ceramic matrix composites. Advances in Ceramic Matrix Composites X. 2004;165:165-179.

47. Beyerle DS, Spearing SM, Evans AG. Damage mechanisms and the mechanical properties of a laminated 0/90 ceramic/matrix composite. J Am Ceram Soc. 1992;75:3321-3330.

How to cite this article: Sevener KM, Tracy JM, Chen Z, Kiser JD, Daly S. Crack opening behavior in ceramic matrix composites. J Am Ceram Soc. 2017;100:4734-4747. https://doi.org/ $\underline{10.1111 / \text { jace. } 14976}$ 